\title{
In vitro comparison of four treatments which discourage infestation by head lice
}

\author{
Kerryn A. Greive • Tanya M. Barnes
}

Received: 11 September 2011 / Accepted: 5 October 2011 /Published online: 27 October 2011

(C) The Author(s) 2011. This article is published with open access at Springerlink.com

\begin{abstract}
Products which discourage the transmission of head lice are appealing; however, few studies have tested this concept. This study aims to test the efficacy of four commercial products which claim to discourage infestation by head lice; MOOV Head Lice Defence Spray (MOOV), Wild Child Quit Nits Head Lice Defence Spray (Wild Child), 100\% Natural Head Lice Beater (Lice Beater) or Lysout Natural Anti-Lice Spray (Lysout). An in vitro challenge test was used. Briefly, one half of a filter paper lining the base of a petri dish was treated with the test product. Lice were then introduced to the centre of the dish, which was covered and placed in the dark at $20^{\circ} \mathrm{C}$ for $30 \mathrm{~min}$. The number of lice on the treated and untreated sides of the filter paper was then counted after 2, 4 and $8 \mathrm{~h}$ post-application. MOOV was significantly more effective at discouraging the transmission of lice than the water control $(p<0.01)$, while Wild Child and Lysout were not at all time points. Lice Beater was significantly worse than the water control after $2 \mathrm{~h}(p<0.01)$, while there was no difference after 4 and $8 \mathrm{~h}$. MOOV was found to perform significantly better than Wild Child $(p<0.05)$ and Lice Beater $(p<0.05)$ at all time points. It also performed significantly better than Lysout at $2(p<0.05)$ and $8 \mathrm{~h}(p<0.05)$, but not $4 \mathrm{~h}$. MOOV offers the best efficacy and consistency of performance of the four products tested to discourage the transmission of head lice.
\end{abstract}

\section{Introduction}

Infestation with head lice (Pediculus humanus capitis) is common, is endemic worldwide, and affects persons of all socioeconomic backgrounds and ages, but is more frequent

K. A. Greive $(\bowtie) \cdot$ T. M. Barnes

Ego Pharmaceuticals Pty Ltd,

21-31 Malcolm Road,

Braeside, VIC 3195, Australia

e-mail: kerryng@egopharm.com between the ages of 3 and 11 years (Frankowski et al. 2002; Burkhart and Burkhart 2005). Head lice are not generally associated with morbidity apart from secondary bacterial infections, however they may cause social stigma, embarrassment, low self-esteem, lost productivity and frustration among all involved (Frankowski et al. 2002; Frankowski 2004). Although the cost of head lice infestation in Australia is unknown, the annual cost in the USA is estimated to be US $\$ 1$ billion (Hansen 2004).

The global control of pediculosis in both developing and developed countries has been hampered not as a result of socioeconomic factors but because of the incorrect use of topical insecticides, and increasing insecticide resistance to commonly used pediculicides including lindane, malathion and permethrin (Downs et al. 2002; Meinking et al. 2002; Hunter and Barker 2003; Thomas et al. 2006). In Australian schools, head lice infestation rates of up to $35.1 \%$ have been reported (Jorm and Capon 1994; Speare et al. 2002), with head lice infestation the third most commonly reported outbreak in day care centres after diarrhoea and conjunctivitis (Jorm and Capon 1994).

The mode of transmission of head lice is the subject of some debate, and opinions are split on the importance of various mechanisms (Canyon et al. 2002); however, the main source of infestation occurs at the classroom level, indicating clustering or close head-to-head contact as the primary cause (Speare and Buettner 1999). Unfortunately, successful treatments are usually short lived as reinfestation is almost guaranteed if associates of the treated person (and their associates) are not treated concurrently (Canyon and Speare 2007). Discouraging head lice transmission is thus important to reduce infestation opportunities. There are many products containing essential oils and other chemicals which can be applied to the hair and claim to discourage head lice transmission. Such products are available from health shops, hairdressers, supermarkets and over the counter from most pharmacies. While these treatments 
sound appealing, the effects associated with these products are only reputed, and very few studies on the efficacy of products to discourage head lice transmission have been published. This study aims to test the efficacy of four commercial products which claim to discourage the transmission of head lice using an in vitro challenge test.

\section{Methods}

Treatments

MOOV Head Lice Defence Spray manufactured by Ego Pharmaceuticals Pty Ltd., Braeside, VIC, Australia containing alcohol, diisopropyl adipate, trimethylpentanediol/adipic acid/ glycerin crosspolymer, and tocopherol. Wild Child Quit Nits Head Lice Defence Spray (AUST L 121653) manufactured by Wild Child (WA) Pty Ltd., West Perth, WA, Australia containing $1.08 \mathrm{mg} / \mathrm{g}$ geranium oil, $830 \mu \mathrm{g} / \mathrm{g}$ lavender oil (Lavendula angustifolia), $100 \mu \mathrm{g} / \mathrm{g}$ eucalyptus oil (Eucalyptus globulus), $500 \mu \mathrm{g} / \mathrm{g}$ santalum spicatum heartwood oil essential (Fusanus spicatus), aqua, polysorbate 20, acetum, alcohol, fragrance, simethicone and cetrimonium chloride. One hundred percent Natural Head Lice Beater (AUST L 73628) manufactured by Essential Health, Southport, QLD, Australia containing pure essential oils including $3.7 \mu \mathrm{l} / \mathrm{ml}$ thyme (Thymus vulgis herb fl.), $2 \mu \mathrm{l} / \mathrm{ml}$ eucalyptus (E. globulus twig leafy), $1.7 \mu \mathrm{l} / \mathrm{ml}$ rosemary (Rosmarinus officinalis herb top $\mathrm{fl}$.), $1.3 \mu \mathrm{l} / \mathrm{ml}$ tea tree (Melaleuca alternifolia twig leafy) and $1.3 \mu \mathrm{l} / \mathrm{ml}$ lavender (L. angustifolia herb top fl.). Lysout Natural Anti-Lice Spray (AUST L 80027) manufactured by National Nature Products, Salisbury, Queensland, Australia containing Echinacea purpurea extract (equivalent to $5 \% \mathrm{w} / \mathrm{v}$ dry root) and $1 \%$ w/v Canarium luzonicum gum oil.

\section{Challenge test}

One half of a Whatman No. $4(90 \mathrm{~mm})$ filter paper was treated with $0.5 \mathrm{ml}$ of one test product, that is either MOOV Head Lice Defence Spray, Wild Child Quit Nits Head Lice Defence Spray, 100\% Natural Head Lice Beater or Lysout Natural Anti-Lice Spray. The other half of the filter paper was left untreated. Water was used as the control. The filter paper was then kept at $37^{\circ} \mathrm{C}$ for the intended period of protection from head lice, that is, either 2,4 or $8 \mathrm{~h}$ before the challenge was performed. The half treated filter paper was then placed onto the base of a clean petri dish ensuring that the entire base was covered. Ten body louse (P. humanus humanus) were then introduced to the centre of the dish, which was covered and placed in the dark at $20^{\circ} \mathrm{C}$ for $30 \mathrm{~min}$. As a result the lice were forced to make a choice between the treated and untreated side of the filter paper. The lice have no third option, thereby eliminating a potential source of error as could occur if the filter paper did not cover the entire base of the petri dish. The number of lice on the treated and untreated sides of the filter paper was then counted. Five replicates were performed using 10 body lice per replicate, to give a total of 50 exposed body lice per test product. The percentage efficacy to discourage body lice transmission was determined by: 1-(percentage body lice on treated side/ percentage body lice on untreated side $) \times 100$.

\section{Statistics}

Unpaired Student's $t$ tests were performed to determine if there was a statistical difference between the numbers of body lice on the treated side of the filter paper after $30 \mathrm{~min}$ exposure as compared to the water control 2,4 and $8 \mathrm{~h}$ post-application to the filter paper. $p<0.01$ was considered significant. A further analysis was performed to determine if the results obtained for MOOV Head Lice Defence Spray were significantly different to the other three test products. $p<0.05$ was considered significant.

\section{Results}

Table 1 shows the total number and the percentage of body lice on the treated and untreated sides of filter paper after 30 min exposure to either MOOV Head Lice Defence Spray, Wild Child Quit Nits Head Lice Defence Spray, 100\% Natural Head Lice Beater, Lysout Natural Anti-Lice Spray or the water control, performed at either 2,4 or $8 \mathrm{~h}$ post-test product application to the filter paper. These data were used to calculate the percentage efficacy to discourage body lice transmission, and statistical analysis was performed.

MOOV Head Lice Defence Spray was significantly more effective at discouraging the transmission of body lice than the water control at all time points $(91.3 \%$ vs $48.5 \%, p=0.0034$ at $2 \mathrm{~h} ; 88.9 \%$ vs $0 \%, p=0.0001$ at $4 \mathrm{~h} ; 88.9 \%$ vs $0 \%, p=0.0029$ at $8 \mathrm{~h}$; Table 2). Wild Child Quit Nits Head Lice Defence Spray $(52.9 \%$ vs $48.5 \%, p=0.829$ at $2 \mathrm{~h} ; 27.6 \%$ vs $0 \%$, $p=0.044$ at $4 \mathrm{~h} ; 48.5 \%$ vs $0 \%, p=0.086$ at $8 \mathrm{~h}$ ) and Lysout Natural Anti-Lice Spray ( $0 \%$ vs $48.5 \%, p=0.049$ at $2 \mathrm{~h}$; $64.9 \%$ vs $0 \%, p=0.014$ at $4 \mathrm{~h} ; 48.5 \%$ vs $0 \%, p=0.100$ at $8 \mathrm{~h}$ ) were not significantly more effective than the water control at any time point (Table 2). One hundred percent Natural Head Lice Beater was significantly worse than the water control at $2 \mathrm{~h}(0 \%$ vs $48.5 \%, p=0.002)$ where it appeared to attract body lice, while at 4 and $8 \mathrm{~h}(0 \%$ vs $0 \%, p=0.504$ and $0 \%$ vs $0 \%$, $p=0.663$, respectively) there was no difference between the performance of either product and the water control (Table 2).

A further analysis was performed to determine if the results obtained for the MOOV Head Lice Defence Spray were significantly different to the other three products. 
Table 1 The total number and percentage of body lice (shown in parentheses) on treated and untreated sides of filter paper after 30 min exposure to four head lice products, 2, 4 and $8 \mathrm{~h}$ post-application to the filter paper

\begin{tabular}{|c|c|c|c|c|c|c|}
\hline \multirow[t]{2}{*}{ Treatment } & \multicolumn{2}{|l|}{$2 \mathrm{~h}$} & \multicolumn{2}{|l|}{$4 \mathrm{~h}$} & \multicolumn{2}{|l|}{$8 \mathrm{~h}$} \\
\hline & $\begin{array}{l}\text { Treated } \\
\text { side }\end{array}$ & $\begin{array}{l}\text { Untreated } \\
\text { side }\end{array}$ & $\begin{array}{l}\text { Treated } \\
\text { side }\end{array}$ & $\begin{array}{l}\text { Untreated } \\
\text { side }\end{array}$ & $\begin{array}{l}\text { Treated } \\
\text { side }\end{array}$ & $\begin{array}{l}\text { Untreated } \\
\text { side }\end{array}$ \\
\hline MOOV Head Lice Defence Spray & $4(8)$ & $46(92)$ & $5(10)$ & $45(90)$ & $5(10)$ & $45(90)$ \\
\hline Wild Child Quit Nits Head Lice Defence Spray & $16(32)$ & $34(68)$ & $21(42)$ & $29(58)$ & $17(34)$ & $33(66)$ \\
\hline $100 \%$ Natural Head Lice Beater & $34(68)$ & $16(32)$ & $40(80)$ & $10(20)$ & $33(66)$ & $17(34)$ \\
\hline Lysout Natural Anti-Lice Spray & $30(60)$ & $20(40)$ & $13(26)$ & $37(74)$ & $17(34)$ & $33(66)$ \\
\hline Water control & $17(34)$ & $33(66)$ & $34(68)$ & $16(32)$ & $30(60)$ & $20(40)$ \\
\hline
\end{tabular}

$n=5$ replicates using 10 head lice per replicate, to give a total of 50 body lice per test product

MOOV Head Lice Defence Spray was found to perform significantly better at discouraging the transmission of body lice than Wild Child Quit Nits Head Lice Defence Spray $(91.3 \%$ vs $52.9 \%, p=0.0196$ at $2 \mathrm{~h} ; 88.9 \%$ vs $27.6 \%$, $p=0.0039$ at $4 \mathrm{~h} ; 88.9 \%$ vs $48.5 \%, p=0.0125$ at $8 \mathrm{~h}$ ) and $100 \%$ Natural Head Lice Beater $(91.3 \%$ vs $0 \%, p=0.0001$ at $2 \mathrm{~h} ; 88.9 \%$ vs $0 \%, p=0.002$ at $4 \mathrm{~h} ; 88.9 \%$ vs $0 \%$, $p=0.0001$ at $8 \mathrm{~h}$ ) at all time points (Table 2). MOOV Head Lice Defence Spray was also found to perform significantly better than Lysout Natural Anti-Lice Spray at all time points with the exception of $4 \mathrm{~h}(91.3 \%$ vs $0 \%, p=0.0012$ at $2 \mathrm{~h} ; 88.9 \%$ vs $64.9 \%, p=0.1919$ at $4 \mathrm{~h} ; 88.9 \%$ vs $48.5 \%$, $p=0.0249$ at $8 \mathrm{~h}$; Table 2). This appears to be due to the highly variable results obtained for Lysout Natural Anti-Lice Spray.

\section{Discussion}

Head lice are attracted to their hosts via a number of factors including humidity, temperature, and a combination of body

Table 2 Percentage efficacy of four head lice products at either 2, 4 or $8 \mathrm{~h}$ post-treatment application

\begin{tabular}{|c|c|c|c|}
\hline \multirow[t]{2}{*}{ Treatment } & \multicolumn{3}{|c|}{$\begin{array}{l}\text { Percentage preventative } \\
\text { efficacy post-application }\end{array}$} \\
\hline & $2 \mathrm{~h}$ & $4 \mathrm{~h}$ & $8 \mathrm{~h}$ \\
\hline MOOV Head Lice Defence Spray & $91.3 *$ & $88.9^{*}$ & $88.9^{*}$ \\
\hline $\begin{array}{l}\text { Wild Child Quit Nits Head Lice } \\
\text { Defence Spray }\end{array}$ & $52.9 * *$ & $27.6^{* *}$ & $48.5^{* *}$ \\
\hline $100 \%$ Natural Head Lice Beater & $0.0 *, * *$ & $0.0 * *$ & $0.0^{* *}$ \\
\hline Lysout Natural Anti-Lice Spray & $0.0 * *$ & 64.9 & $48.5^{* *}$ \\
\hline Water control & 48.5 & 0.0 & 0.0 \\
\hline
\end{tabular}

$n=5$ replicates using 10 body lice per replicate, to give a total of 50 body lice per test product

${ }^{*} p<0.01$ vs water control; ${ }^{* *} p<0.05$ vs MOOV Head Lice Defence Spray odours and chemicals (Mumcuoglu et al. 1996, 2004). Head lice are very particular in regards to selecting a new host and will only transfer hosts when conditions are optimal (Canyon et al. 2002). An effective product would benefit a potential host by altering their scalp environment thereby making conditions suboptimal for head lice. Under such conditions head lice are less likely to commit to a host transfer.

Head lice are yet to be successfully colonized. Human body lice as opposed to head lice were studied in these experiments. Body lice can be kept alive in the laboratory for long periods of time by feeding them on rabbits which cannot be done for head lice, who will only feed off humans. While it is well recognised that there are distinct morphological differences between human head lice and body lice, it has been demonstrated using mDNA that they are conspecific, that is they represent the one species (Leo et al. 2002). Therefore the use of human body lice as a surrogate for human head lice is not unreasonable.

A challenge test using filter paper in a closed petri dish rather than hair on a human head was used to test the four products since it gives the lice two choices only: a surface with test product or without test product. If we had used hair covered in test product in a petri dish to determine if lice wanted to be on the hair or off the hair, the lice may not have gone on the hair by chance rather than choice given the limited surface area of hair compared with the petri dish. Lice like the dark, so they could have used the shade of the treated hair to escape the light when the petri dish was brought out for inspection. A recent study has demonstrated the difficulties of testing this type of product on hair compared with paper (Semmler et al. 2011). In this study, lice were placed on horizontal treated hair hung up vertically so that they would have a chance to let themselves drop down onto the soil. However, they decided to stay and crawl upwards apparently "hoping" to reach "better smelling" regions of the hair (Semmler et al. 2011).

MOOV Head Lice Defence Spray was found to be significantly more effective at discouraging the transmission of body lice than the water control, Wild Child Nits Head Lice 
Defence Spray, $100 \%$ Natural Headlice Beater, and Lysout Natural Anti-Lice Spray for up to $8 \mathrm{~h}$. MOOV Head Lice Defence Spray leaves a residue on hair once the alcohol from the product rapidly evaporates consisting of diisopropyl adipate, trimethylpentanediol/adipic acid/glycerin crosspolymer and tocopherol. Head lice find this residue "dirty" and unattractive and thus are discouraged from infesting hair which has been treated with this product. The ingredients in the residue, individually or in combination, do not have any known repellency action like that shown for diethyltoluamide (DEET).

With the increasing global prevalence of pediculosis, the number of products claiming to discourage the transmission of head lice available over the counter has increased dramatically. However, the effects associated with these products are only presumed, and very few studies on the efficacy of products to discourage head lice transmission have been published. For example, in vitro studies have found that essential oils such as rosemary (Mumcuoglu et al. 1996), lavender (Burgess 1993a), piperonal (Burgess 1993b; Peock and Maunder 1993), eucalyptus (Mumcuoglu et al. 1996; Toloza et al. 2006, 2008) and citronella (Mumcuoglu et al. 1996) are promising candidates as compounds which discourage the transmission of head lice; however, formulation into suitable products for commercial use has not been studied. Components of some essential oils such as 1,8cineole (Toloza et al. 2008), anisole (Toloza et al. 2006; 2008) and chavibetol (Bagavan et al. 2011) have also been shown to be possible candidates. One in vitro study found that several commercially available products including DEET did not show sufficient efficacy to discourage head lice transmission to be endorsed (Canyon and Speare 2007). Another in vitro study found that DEET, icaridin, and IR 3535 only discouraged head lice for $2 \mathrm{~h}$ when applied to hair, while three commercial products, Linicin Preventive Spray (Semmler et al. 2011) formerly named Licatack Preventive Spray (Semmler et al. 2010, 2011) containing paramenthandiol (PMD) and an extract of the Vitex agnus-castus plant, as well as Picksan NoLice containing PMD and a neem seed extract (Semmler et al. 2011), discouraged head lice for a prolonged period of time. In the only clinical trial published to date, a slow release citronella formulation was found to be safe and effective at discouraging head lice transmission in children (Mumcuoglu et al. 2004).

This study has shown that out of the four head lice repellents tested, MOOV Head Lice Defence Spray offers the best efficacy and consistency of performance. Use of an effective product which discourages the transmission of head lice could significantly lower the incidence of reinfestation, which among other beneficial effects would lower expenditure on head lice control and the time spent on treatment and removal of lice. No less important would be the psychological and social benefits gained by eliminating the stigma and social isolation associated with louse infestation.
Conflicts of interest Kerryn Greive and Tanya Barnes are employed by Ego Pharmaceuticals, the manufacturer of MOOV Head Lice Defence Spray.

Open Access This article is distributed under the terms of the Creative Commons Attribution Noncommercial License which permits any noncommercial use, distribution, and reproduction in any medium, provided the original author(s) and source are credited.

\section{References}

Bagavan A, Rahuman AA, Kamaraj C, Elango G, Zahir AA, Jayaseelan C, Santhoshkumar T, Marimuthu S (2011) Contact and fumigant toxicity of hexane flower bud extract of Syzygium aromaticum and its compounds against Pediculus humanus capitis (Phthiraptera: Pediculidae). Parasitol Res (in press)

Burgess I (1993a) The function of repellent in head louse control. Pharmaceut J 15:674-675

Burgess I (1993b) New head louse repellent. Br J Dermatol 128:357-358

Burkhart CN, Burkhart CG (2005) Head lice: scientific assessment of the nit sheath with clinical ramifications and therapeutic options. J Am Acad Dermatol 53:129-133

Canyon DV, Speare R (2007) A comparison of botanical and synthetic substances commonly used to prevent head lice (Pediculus humanus var. capitis) infestation. Int J Dermatol 46:422-426

Canyon DV, Speare R, Muller R (2002) Spatial and kinetic factors for the transfer of head lice (Pediculus capitis) between hairs. J Invest Dermatol 119:629-631

Downs AM, Stafford KA, Hunt LP, Ravenscroft JC, Coles GC (2002) Widespread insecticide resistance in head lice to the over-thecounter pediculocides in England, and the emergence of carbaryl resistance. Br J Dermatol 146:88-93

Frankowski BL (2004) American Academy of Pediatrics guidelines for the prevention and treatment of head lice infestation. Am J Manag Care 10:S269-S272

Frankowski BL, Weiner LB, Committee on School Health the Committee on Infectious Diseases, American Academy of Pediatrics (2002) Head lice. Pediatrics 110:638-643

Hansen RC (2004) Economic considerations associated with Pediculosis humanus capitis infestation. Clin Pediatr 43:523-527

Hunter JA, Barker SC (2003) Susceptibility of head lice (Pediculus humanus capitis) to pediculicides in Australia. Parasitol Res 90:476-478

Jorm LR, Capon AG (1994) Communicable disease outbreaks in long day care centres in western Sydney: occurrences and risk factors. J Pediatr Child Health 30:151-154

Leo NP, Campbell NJ, Yang X, Mumcuoglu K, Barker SC (2002) Evidence from mitochondrial DNA that head lice and body lice of humans (Phthiraptera: Pediculidae) are conspecific. J Med Entomol 39:662-666

Meinking TL, Serrano L, Hard B, Entzel P, Lemard G, Rivera E, Villar ME (2002) Comparative in vitro pediculicidal efficacy of treatments in a resistant head lice population in the United States. Arch Dermatol 138:220-224

Mumcuoglu KY, Galun R, Bach U, Miller J, Magdassi S (1996) Repellency of essential oils and their components to the human body louse, Pediculus humanus humanus. Entomol Exp Appl 78:309-314

Mumcuoglu KY, Magdassi S, Miller J, Ben-Ishai F, Zentner G, Helbin V, Friger M, Kahana F, Ingber A (2004) Repellency of citronella for head lice: double-blind randomized trial of efficacy and safety. Isr Med Assoc J 6:756-759 
Peock S, Maunder JW (1993) Arena tests with piperonal, a new louse repellent. J R Soc Health 113:292-294

Semmler M, Abdel-Ghaffar F, Al-Rasheid K, Klimpel S, Mehlhorn H (2010) Repellency against head lice (Pediculus humanus capitis). Parasitol Res 106:729-731

Semmler M, Abdel-Ghaffar F, Al-Quraishy S, Al-Rasheid KA, Mehlhorn H. (2011) Why is it crucial to test anti-lice repellents? Parasitol Res (in press)

Speare R, Buettner PG (1999) Head lice in pupils of a primary school in Australia and implications for control. Int J Dermatol 38:285-290

Speare R, Thomas G, Cahill C (2002) Head lice are not found on floors in primary school classrooms. Aust NZ J Public Health 26:208-211
Thomas DR, McCarroll L, Roberts R, Karunaratne P, Roberts C, Casey D, Morgan S, Touhig K, Morgan J, Collins F, Hemingway J (2006) Surveillance of insecticide resistance in head lice using biochemical and molecular methods. Arch Dis Child 91:777-778

Toloza AC, Zygadlo J, Cueto GM, Biurrun F, Zerba E, Picollo MI (2006) Fumigant and repellent properties of essential oils and component compounds against permethrin-resistant Pediculus humanus capitis (Anoplura: Pediculidae) from Argentina. J Med Entomol 43:889-895

Toloza AC, Lucia A, Zerba E, Masuh H, Picollo MI (2008) Interspecific hybridization of Eucalyptus as a potential tool to improve the bioactivity of essential oils against permethrin-resistant head lice from Argentina. Bioresour Technol 99:7341-7347 